Participants also reported that they avoided treatment to feel normal, and that they thought it acceptable because they did not initially perceive any negative consequences from nonadherence. YP valued different members of their healthcare team taking an interest in their lives and giving them opportunities to talk about such thoughts and feelings. Robust staff support mechanisms should capture YP experiencing challenging life events. Additionally, peer support through peer mentorship or peer-group support was greatly valued and deemed protective against nonadherence.

\section{G549(P) THE IMPACT OF WRITTEN INFORMATION ON PATIENTS MOVING THROUGH THE TRANSITION FROM PAEDIATRIC TO ADULT HEALTHCARE; A CO-PRODUCED PATIENT EXPERIENCE STUDY}

${ }^{1} \mathrm{R}$ Bain, ${ }^{2} \mathrm{~A}$ Battersby, ${ }^{2,3} \mathrm{~J}$ Ball, ${ }^{3}$ Members of YPAGne, ${ }^{1} \mathrm{~A}$ Wallace, ${ }^{2} \mathrm{~A}$ Bowey, ${ }^{2} \mathrm{H}$ Charters, ${ }^{2,3} \mathrm{~N}$ Davidson. 'Faculty of Medical Sciences, Newcastle University, Newcastle upon Tyne, UK; ${ }^{2}$ Great North Children's Hospital, Newcastle upon Tyne Hospitals NHS FT, Newcastle upon Tyne, UK; ${ }^{3}$ Young Person's Advisory Group North England, Newcastle upon Tyne Hospitals NHS FT, Newcastle upon Tyne, UK

\subsection{6/archdischild-2020-rcpch.466}

Aims NICE guidance (NG43) recommends that planning for a young person transitioning into adult healthcare should start at 13-14 years. An integral part of transition planning is educating both patient and carers about what is going to happen during transition. We aimed to demonstrate how written information is being distributed and what role it plays on patient experience.

Methods A survey about patient experience was co-designed with young people. The survey was delivered by researchers and young people in all outpatient departments in a tertiary paediatric hospital. Patients and their carers were asked to complete a survey about their experience. Staff were surveyed about departmental practice in transition information.

Results 556 paediatric patients completed the survey. We found that $13.0 \%$ of patients reported receiving transition information (median age 16 years). When patients were asked what would make them feel more prepared for transition, $77 \%$ would like more information relating to transition. Patients who received written information reported it as 'Useful' or 'Very useful' (48/63, 76.2\%). Patients who received written information on transition had a better care experience (mean increase $11.3 \%, \mathrm{p}=0.0004$ ), improved self-perceived preparedness (mean increase $32.4 \%, \mathrm{p}<0.0001$ ) and a reduction in anxiety relating to transition (mean reduction $8.1 \%$, $\mathrm{p}=0.0017$ ).

The analysis of 271 carer responses is shown. Carers of patients showed similar findings with an improvement in carer care experience $(6.2 \%, \mathrm{p}=0.025)$, a reduction in transition anxiety $(31.9 \%$ reduction, $\mathrm{p}<0.0001)$ and an increase self-perceived preparedness $(11.2 \%, \mathrm{p}=0.0008)$.

Staff were asked if their service handed out information on transition, with $24 / 58(41.4 \%)$ reporting that their service did give out written information.

Conclusions Our study suggests that having written transition information has an association with an improved care experience, reduced transition anxiety and feeling more prepared for the transition in paediatric and carer groups. Information on transition is thus highly effective. However, it is clear that more written information on transition should be provided to empower carer and patient groups about the transition into adult healthcare.

\section{G550(P) WHAT MATTERS TO FAMILIES OF CHILDREN WITH COMPLEX MEDICAL NEEDS? CO-DESIGNING AN INFORMATION LEAFLET FOR CHILDREN WITH COMPLEX MEDICAL NEEDS}

${ }^{1} \mathrm{~J}$ Gough, ${ }^{1} \mathrm{~S}$ Roberts, ${ }^{2} \mathrm{~T}$ Gray, ${ }^{3} \mathrm{R}$ Sheeley, ${ }^{4} \mathrm{~S}$ Neilson, ${ }^{5} \mathrm{~L}$ Pawlak, ${ }^{6} \mathrm{C}$ Wicks, ${ }^{1} \mathrm{R}$ Ramachandran. 'General Paediatrics, Evelina London Childrens Hospital, London, UK; ${ }^{2}$ Patient Engagement Team, Evelina London Childrens Hospital, London, UK; ${ }^{3}$ Occupational Therapy, Evelina London Childrens Hospital, London, UK; ${ }^{4}$ Physiotherapy, Evelina London Childrens Hospital, London, UK; ${ }^{5}$ Well Child Charity, London, UK; ${ }^{6}$ Community Paediatrics, Evelina London Childrens Hospital, London, UK

\subsection{6/archdischild-2020-rcpch.467}

Aim To improve communication between healthcare professionals and families/carers of children with complex medical needs, we co-designeda patient information booklet, to be given on admission to our ward.

Methods A focus group involving six families of children with medically complex needs was held with the aid of our Patient Engagement lead. Four questions were asked:

- In hindsight, what information do you wish you had known or been given on admission to hospital or following diagnosis?

- What information could we give you that would make your lives easier?

- What advice would you give other parents in a similar situation?

- What other resources or contacts have helped you?

The resulting information informed the creation of a patient information booklet.

Results The work highlighted the importance of seeking patient input, whilst our anticipation had been a focus on medical information, their desire was for much more practical information related to their wider context. Reflecting their longer stay; knowledge of accommodation, food choices and parking were key with one family highlighting they had spent $£ 1000$ on parking. In keeping with literature reporting on the high psychosocial and financial burden on these families, information on how to get financial support and signposting to charities that aided with this were valued. Interestingly families had mixed feelings about parent run support groups. Results also made us question common ward practices with parents talking of the emotional distress caused by repeatedly recounting their child's, often difficult, medical journey. Many found being part of multidisciplinary meetings overwhelming and wanted greater choice over how they were involved. They wanted the important role of allied health professionals to be clearer from the start. Stories also illustrated how misleading commonly used medical phrases such as 'Delayed development' can be. Amongst the advice they would give to families they commented on the importance of not losing hope and trusting your own parental instinct; as a result families' own stories and words of advice have been included in the information leaflet.

Conclusion The involvement of families is vital in co-designing any information given to families of children with complex medical needs. 